\title{
PROMOTING ZERO EMISSIONS BUSES PROGRAMS: A STUDY OF EKATERINBURG RESIDENTS' WILLINGNESS TO PAY
}

\author{
GABRIEL PEDROSA $^{1}$, YULIA LEONTYEVA ${ }^{2} \&$ IGOR MAYBUROV $^{3}$ \\ ${ }^{1}$ University of Aveiro, Aveiro, Portugal. \\ ${ }^{2}$ Ural Federal University, Ekaterinburg, Russian Federation. \\ ${ }^{3}$ Ural Federal University, Ekaterinburg, Russian Federation.
}

\begin{abstract}
Transports are among the major sources of atmospheric pollution, causing climate change and public health damage. Public transportation is a well-known, recognized solution to greatly decrease transport emissions, especially when making use of zero emissions buses in the fleet, such as buses driven by batteries or by hydrogen. However, cost imposes a large barrier on zero emissions buses. The transition to the use of such buses is expensive, and it must be driven by several stakeholders, thus motivating service providers to make efforts towards zero emissions buses implementation strategies. In this study, citizens from a Russian district capital city were questioned on their potential role as contributors to the zero emissions buses transition, by studying their willingness and attitudes to pay a premium for the bus fares, in order to supplement the public transport agencies revenues. It was found that environmental concern and air pollution concern can be critical factors driving consumers into paying premium, but not noise pollution. Based on this study, there are several recommendations proposed for practitioners, as well as several future research avenues. In this article we seek to investigate how the consumers' attitudes and concerns over the environment and city pollution could influence their willingness to play a role as supporters of the introduction of zero emissions buses in the public transportation fleet, since understanding the consumer attitudes is essential to perform and run an efficient public system.

Keywords: Air Pollution, Public Marketing, Transportation Policy, Willingness to Pay, Zero Emissions Buses.
\end{abstract}

\section{INTRODUCTION}

Climate change and public health are two global issues that arise from the use of fossil fuels in transports and need to be addressed urgently [1]-[3]. Public transport is generally regarded as a sustainable mode of transportation, as emissions per passenger are lower than those of automobiles, although, conventional diesel buses contribute to air and noise pollution, especially in high density areas [4]-[6]. However, promising alternatives to the conventional fossil-fueled engines are making their way into buses used in public transportation - the most promising of which are the battery-electric and the hydrogen fuel-cells powered engines, more energy-efficient and far less pollutant than the conventional diesel engines [2], [3], [7]. Buses using either of these two fuel technologies will be referred hereafter to zero emission buses (ZEBs), as neither type generates any pollutant emission. ZEBs also have specific advantages over trolley buses and trams, such as the flexibility of use of road infrastructure without the need for powerlines or rails. This means that large urban areas will not need heavy modifications, powerlines will not be affected by extreme weather conditions, and route planning flexibility is kept [4], [5].

Despite rapid growth in the number of running ZEBs, global adoption remains marginal when compared to conventional buses. Although cities such as Hamburg (Germany), London

\footnotetext{
${ }^{1}$ ORCID: http://orcid.org/0000-0001-8463-7962

${ }^{2}$ ORCID: http://orcid.org/0000-0003-4676-9926

${ }^{3}$ ORCID: http://orcid.org/0000-0001-8791-665X
} 
(United Kingdom), Paris (France) and Barcelona (Spain) are already phasing out conventional fuel buses, these still represent most of the public transportation fleet worldwide [8]. In 2012, fully electric buses represented $6 \%$ of the new global bus purchases, and were predicted to reach $15 \%$ by 2020 . The transition to their large scale use in public transportation is still in the early stages due mainly to limited driving range and acquisition costs. These vehicles are more expensive to procure than conventional buses: an electric bus will cost in the range of $€ 350,000-500,000$, whereas a diesel bus will cost $€ 200,000-250,000$ - cost remains a major adoption barrier [3], [9], [10]. Additionally, either electric or hydrogen recharging stations need to be installed, and these drive up the cost of ZEB operations as they are more expensive than conventional diesel stations [8]. As the price barrier is typically regarded as an exogenous barrier that is beyond the reach of the actors in the public transportation sector, authorities and operators postpone investments until conditions to upgrade are present. This is especially relevant as public transport companies have limited budgets: to renew or modify the vehicle fleet is a large investment and the decision is dependent on public funds distribution [8], [11]-[14]. Furthermore, central government funding can be dispersed nation-wide, leading to medium and small-size cities to be under-funded. This situation is complicated further by the recent introduction of marketing in the public sector, which has been one of the most overlooked and misunderstood fields in this area [15]. Tax and other fiscal instruments for stimulating such vehicles have not been sufficiently developed and could be improved [16]-[19]. At the same time the improvement of the tax system and other fiscal instruments to stimulate the extensive use of vehicles using battery-electric and hydrogen fuel-cells power units is required.

However, despite being especially relevant that sales are an important source of revenue, sometimes making up to $50 \%$ of the total revenue, research on the consumers' side of ZEBs is insufficient. Mahmoud et al. [10] provided a literature review on ZEBs on the domains of technology, environment, economy and energy, but omit to consider the user side of the equation. Mohamed et al. [12] noted that research about electric bus adoption is well advanced in technological, environmental, operational and life-cost domains, but insufficient in the stakeholders' attitudes towards adoption. Still, these authors omit to name users as potential contributors in the pursue of ZEB adoption. This situation occurs in other studies, such as the one by Bakker and Konings [8], who suggested several alternatives for public transportation companies to overcome the difficulties and barriers to ZEBs adoption, such as inviting additional actors to invest or subcontracting providers, but, they also omit to suggest the users' role.

Although there are studies in the literature addressing the public's willingness to pay (WTP) for environmental-friendly buses [4], [20], [21], these do not consider the role of the respondents' environmental or pollution concerns in the WTP. Similar studies have analyzed the peoples' willingness to pay for improvements in road traffic to prevent health risks derived from air and noise pollution, but, exclusively in the form of annual taxes [22], [23].

In this article we seek to investigate how the consumers' attitudes and concerns over the environment and city pollution could influence their willingness to play a role as supporters for the introduction of ZEBs in the public transportation fleet, since understanding the consumer attitudes is essential to perform and run an efficient public system [15]. The following section presents a literature review with the hypothesis development. The third section introduces the methods, describing the survey. The fourth and fifth sections present the results and final discussions, respectively. In the final section there are provided recommendations for public transport managers and policy makers and a list of promising future research venues.

\section{LITERATURE REVIEW AND HYPOTHESIS DEVELOPMENT}

The societal marketing concept points that organizations should deliver superior value to customers in a way that maintains or improves consumers' and society well-being [15]. 
Public transports have advantages and contribute to society by providing a transportation option that uses fewer resources and is more environmental-friendly. This is especially true in the case of ZEBs [5]. In this case, increased use of ZEBs cannot only give direct value to the users, but also to the society, through benefits such as less air and noise pollution, less car traffic, less road accidents and fatalities, and better transportation services and options.

In the case of ZEBs, research gives out contradictory and varying results in the public willingness to pay a higher fee to enable their introduction to service, despite positive respondents' attitudes towards environmental friendly technologies [24]. Next, the environmental, air pollution and noise pollution concerns are presented as antecedents of WTP.

The individuals' concern with the environment can influence their attitudes, hence their behaviour. Stern et al. [25] developed a model for the individuals' environmental concern based on the belief of consequences for society, for the self and for the biosphere that in turn motivates a behavior. Environmental concern is defined as the degree to which individuals are aware of problems regarding the environment and support the effort to solve them or indicate willingness to contribute personally to a solution [26]. Individuals who have a high environmental concern will be more inclined to purse a 'green' purchasing behavior [27]. Environment is regarded as an important key factor for the choice of public transportation [21], [28], [29]. Thus, the following hypotheses are developed:

H1: Environmental concern has a positive relationship with attitude towards ZEBs.

H2: Environmental concern has a positive relationship with WTP for ZEBs.

Albeit emission improvements were enforced by successive Euro emission standards, road transit generates several air pollutants (including sulphur dioxide, nitrogen dioxide, fine particulate matter, carbon monoxide and carbon dioxide) which have negative impacts on the population leading to health problems and premature deaths [5, 30]. Another growing environmental problem is the transport noise, which affects especially urban residents [31], [32]. Several studies show that traffic noises cause non-auditory stress effects and affect the psychological system, leading to high blood pressure, sleep disturbance, annoyance and other disturbances [33]. A study specifically on road traffic noise effects found similar symptoms, including tiredness, headaches and nervous stomach [31], [33].

Air and noise pollution are important outcomes of road traffic that have significant effects on physical and mental factors of functional health and wellbeing [34]. The consumers' intentions can be measured by the amount of money they are willing to pay for project or modification of a product that would provide a better environmental performance such as lowering city air and noise [4]. In this study, it is hypothesized that people who are more concerned about air and noise pollution will be more supportive of projects to reduce road traffic noise, hence, having a more positive attitude and more willing to pay extra to support the use of ZEBs. Hence the following hypotheses are generated:

H3: Air pollution concern has a positive relationship with attitude towards ZEBs.

H4: Air pollution concern has a positive relationship with WTP for ZEBs.

H5: Noise pollution concern has a positive relationship with attitude towards ZEBs.

H6: Noise pollution concern has a positive relationship with WTP for ZEBs.

\section{METHOD}

\subsection{Sample}

Data was collected in the city of Ekaterinburg (Russian Federation) through an online questionnaire. The city of Ekaterinburg is one of the major industrial center of Russia, with a population of about 1.5 million people (54\% women, $46 \%$ men), with over $60 \%$ of the 
population being between 16 and 59 years old. The city is compact, occupying an area of about 1.14 thousand $\mathrm{km}^{2}$, with a population density of 1293 people $/ \mathrm{km}^{2}$. In 2002 the annual passenger quantity of municipal transport was 647.1 million people. However, this number has declined slightly through the years, due to factors such as an aging public vehicles fleet and an increase in the use of private cars. In 2009 the annual passenger value was of 412 million people (almost $40 \%$ less than in 2002).

In Ekaterinburg several types of public transport are represented: buses, fixed-route taxis, trolleybuses and trams. The bus system in Ekaterinburg is the most used public transportation mode with an annual passenger value of about 95 million passengers. There are 60 bus routes, and up to 100 buses operation simultaneously in peak hours. There are currently 250 trolleybuses serving 19 routes and carried 34.1 million people in 2013. There are 459-tram wagon operating in 30 routes, which carried 93.7 million people in 2014. The fixed-route taxi is operated by several carriers on 60 routes.

Transportation of passengers is carried out by municipal transport, as well as by commercial transport, the total number of organizations carrying out passenger transportation is about 50, and more than half of the passengers are transported by municipal transport. Private organizations carry out transportation by bus and fixed-route taxis. According to the head of the committee on transport in 2016, municipal transport enterprises got total revenues amounting to 3.8 billion rubles ( 51 million euros), and expenses 5.3 billion rubles ( 71 million euros). Losses ( 1.5 billion rubles-20 million euros) were covered by the city budget.

\subsection{Data collection tool}

The online tool available at www.typeform.com was employed to host the questionnaire, which is compatible with PC, smartphones and tablet systems. The questionnaire was divided into three sections. First, respondents were presented a short introduction about the study and questioned about the usage frequency of public transportations, the cost of a typical bus ticket, their level of environmental, air and noise concerns. Environmental concern was measured using two items, based on the study from Refs. [35], [36] on the environmental concerns and attitudes: 'To what extent are you concerned about the situation of the environment in general?' and 'To what extent do you consider yourself in favor of the defense of the environment?'. Respondents answered in a five-point Likert scale ranging from 1 (not at all), to 5 (very much). Although more complete scales were available in research [26], in a similar study [35] it was argued that this simpler scale had the advantage of not conflating concern with worldviews, behavioral intentions or attitudes. Pollution concern was measured by two items based on [22], one for air and one for noise: 'Please rate your level of concern with the effects of air/noise pollution from road traffic effect on your health' in a five-point Likert scale ranging from 1 (not at all concerned), to 5 (very concerned). Following the method, respondents were informed about the health risks for both air and noise pollution before measuring their level of concern.

The second section started describing ZEBs' technical characteristics and advantages, followed by asking respondents about their attitude towards ZEBs. WTP was measured by asking the willingness of the respondents to pay a higher fee to enable ZEBs to take place in the urban transport system [29]. The final section was about demographic variables, including gender, age, occupation and income.

\section{RESULTS}

The questionnaire was distributed by email in March-May of 2018 in the city of Ekaterinburg. 258 responses were collected, thus bringing the completion rate to almost $44 \%$. Of the 
sample, $70 \%$ are female, $55 \%$ do not own a car, and live in Ekaterinburg. The majority of respondents $(n=49,6 \%)$ were frequent users of public transport, using it daily or a few times a week. Table 1 displays several descriptive profiles of the respondents.

The level of satisfaction with the quality of transport is generally positive (mean $=3.56$ ) but when questioned about public transportation improvement suggestions, 90\% ( $\mathrm{n}=77)$ of the respondents gave suggestions. The most pointed suggestions were: to increase the number of buses; to increase the availability and accuracy of schedules and timetables information; to improving culture, behaviour and professionalism of drivers; to implement a mobile paying mode; to allocate more bus lanes in the city; to improve cabin comfort (air conditioning, handrails, seats); to install lower steps; to not overload buses. The upgrade of buses to more modern buses was also mentioned, and a higher number of buses and routes, especially at peak hours. Four respondents suggested improvements towards a better environmental performance, and only seven respondents suggested decreasing the transport usage cost, which indicates that the bus fare price is not perceived as high.

As Table 2 shows, there were noted positive levels of environment concern (mean $=3.93$ ) and also concerns about the impact of air and noise pollution on health (mean $=4.01$ and mean $=3.59$, respectively). The sample is generally positive about ZEBs (mean $=4.5$ ).

The average bus fare cost pointed by respondents was $€ 0.42$. The most common value for a bus fare (mode) pointed by 168 participants $(67 \%)$ was $€ 0.37$. The bus fare system in Ekaterinburg is not dependent on the bus trip duration.

When questioned about their WTP to support the ZEBs, 45 respondents (17.4\%) answered a zero value. Considering only the respondents that pointed a value for WTP, the WTP average was of $€ 0.29$ (over $78 \%$ of the regular bus fare price). The most common pointed values were $€ 0.07$ by 45 participants (over $19 \%$ of the regular bus fare price) and $€ 0.40$ by 39 participants (over $100 \%$ of the regular bus fare price).

Table 1: Profiles of respondents.

\begin{tabular}{lcc}
\hline Measure & Items & Percentage \\
\hline Gender & Female & $70 \%$ \\
Age & Male & $30 \%$ \\
& $18-25$ & $63 \%$ \\
& $26-30$ & $5 \%$ \\
& $31-40$ & $9 \%$ \\
Professional situation & $41-50$ & $14 \%$ \\
& 51 or older & $9 \%$ \\
Bus use & Student & $63 \%$ \\
& Working & $36 \%$ \\
& Unemployed & $1 \%$ \\
& Less than a few times a month & $27 \%$ \\
& Several times a month & $16 \%$ \\
& A few times a week & $14 \%$ \\
& Daily / Almost daily & $43 \%$ \\
\hline
\end{tabular}


Table 2: Univariate Descriptive Mean and standard deviation.

\begin{tabular}{lcc}
\hline Variable & Mean & SD \\
\hline Environmental concern & 3.93 & 0.930 \\
Air pollution concern & 4.01 & 0.888 \\
Noise pollution concern & 3.59 & 1.045 \\
ZEB attitude & 4.50 & 0.778 \\
\hline
\end{tabular}

\section{HYPOTHESIS TESTING}

All hypotheses entailed a relationship between two variables. In order to test the hypotheses, a correlation statistical test was selected. First, variables were tested for normality using the Shapiro-Wilk test: significance on all variables was of 0.000 , so the null hypothesis is rejected, meaning that there were no normal distributions. Hence, the Spearman test was selected to measure the degree of association between variables, as it does not carry assumptions about the distribution of the data. This coefficient (rho) varies from -1 to +1 , depending on whether the association is negative or positive, respectively.

The environmental concern was found to be positively associated with air pollution concern $($ rho $=0.526 ; \mathrm{p}=0.000)$, with noise pollution concern (rho $=0.396 ; \mathrm{p}=0.000$ ), and with WTP (rho $=0.241 ; p=0.025$ ). Air pollution concern was positively associated with noise pollution concern (rho $=0.490 ; p=0.000$ ), with ZEB attitude (rho $=0.291 ; p=0.007$ ) and with WTP ( $r$ o $=0.268 ; \mathrm{p}=0.013$ ). The remaining associations were not considered statistically significant. Table 3 displays the results from the correlation analysis.

The hypothesis analysis results are summarized in Table 4. Environmental concern was found to be significantly associated with attitude towards ZEBs, confirming H1, but not with WTP towards ZEBs, rejecting H2. Air pollution concern was found to be significantly associated with both attitude towards ZEBs and WTP for ZEBs, thus confirming H3 and H4. Noise pollution concern was not found to be associated with neither attitude towards ZEBs nor WTP for ZEBs; hence, both H5 and H6 are rejected.

Table 3: Spearman Correlation Coefficients.

\begin{tabular}{llllll}
\hline Variable & $\begin{array}{l}\text { Environmental } \\
\text { concern }\end{array}$ & $\begin{array}{l}\text { Air pollution } \\
\text { concern }\end{array}$ & $\begin{array}{l}\text { Noise } \\
\text { pollution } \\
\text { concern }\end{array}$ & $\begin{array}{l}\text { ZEB } \\
\text { attitude }\end{array}$ & WTP \\
\hline $\begin{array}{l}\text { Environmental } \\
\text { concern }\end{array}$ & 1 & & & \\
$\begin{array}{l}\text { Air pollution } \\
\text { concern }\end{array}$ & $0.526^{* *}$ & 1 & & & \\
$\begin{array}{l}\text { Noise pollution } \\
\text { concern }\end{array}$ & $0.396^{* *}$ & $0.490^{* *}$ & 1 & & \\
$\begin{array}{l}\text { ZEB attitude } \\
\text { WTP }\end{array}$ & 0.135 & $0.291^{* *}$ & 0.208 & 1 & \\
\hline
\end{tabular}

$* *$ Correlation is signification at the 0.01 level (2-tailed).

*Correlation is significant at the 0.05 level (2-tailed). 
Table 4: Summary of results.

\section{Hypothesis Description}

\section{Result}

$\mathrm{H} 1$

$\mathrm{H} 2$

H3

$\mathrm{H} 4$

H5

H6
Environmental concern has a positive relationship with attitude towards ZEBs.

Environmental concern has a positive relationship with WTP for ZEBs.

Air pollution concern has a positive relationship with attitude towards ZEBs.

Air pollution concern has a positive relationship with WTP for ZEBS.

Noise pollution concern has a positive relationship with attitude towards ZEBs.

Noise pollution concern has a positive relationship with WTP for ZEBS.
Not accepted

Accepted

Accepted

Accepted

Not accepted

Not accepted

\section{CONCLUSION}

Buses move about half of all transit passengers in Europe, playing a major role in competing with passenger cars in terms of efficiency, emissions and safety [1]. ZEBs offer different operations characteristics when compared to traditional diesel buses, and even if other transportation modes have specific advantages (like rail), the bus is likely to continue to play a major role in servicing public transport needs [5]. ZEBs are a promising solution to improve urban and sub-urban life quality but the transition to ZEBs is expensive, and it must be driven by several stakeholders, thus motivating service providers to make efforts into the ZEB implementation strategies [12].

The objective of this study was to investigate how the consumers' concerns over the environment and pollution could influence the attitude and willingness to pay for the introduction of ZEBs. A final discussion along with recommendations for practice is presented, followed by the study's limitations and future research avenues.

\subsection{Discussion}

As per other studies, people are generally positive about new environmental-friendly transportations [29]. The environmental concern was not found to be related with the ZEB attitudes, but it did with WTP. Other researchers have reached the same conclusion, albeit stating a weak relation between environmental concern and behavior [36], [37]. Other studies have not found environmental concern to be a factor in the willingness to pay more for ecofriendly buses [29]. Hence, in the case of ZEB introduction supported by increased price of bus fare, the consumers' environmental concern has a questionable relevancy. More research into the actual link between environmental concern and WTP is deemed necessary.

On the other hand, the air pollution concern was found to be associated with both ZEB attitude and WTP. This is one of the key conclusions in this study, as it shows that concern for the air quality is relevant to the attitude and behavioral intentions towards ZEBs. This conclusion is in line with WTP for decrease in air pollution [4], [22], [23]. However, contrary to 
these studies, noise pollution was not found to be associated with WTP. One possible explanation is that the buses are not seen as one of the major noise sources, as would be neighbors, traffic or industrial activities. More research on understanding the noise pollution landscape and the people's rating of noise sources and sensitivity is here advised.

WTP intentions for ZEBs are different among regions and countries [29]. In this study, it was found that a majority of respondents would be willing to pay for the implementation of ZEBs. The average WTP value was of $€ 0.29$, which corresponds to roughly $78 \%$ of the most common bus fare price. An increase in bus fare price of this size would appear to be relevant; however, one must consider the absolute value added, as the fares are low priced. Heo and Yoo [20] estimated the total monetary gain from the average WTP by multiplying it by the number of users. Considering an annual transportation of 95 million passengers for the bus system alone, and an average $€ 0.29$ value for the extra fare, this would create an extra revenue of 27.6 million euros. Even a temporary increase in bus fares, for example for a few months would provide sufficient revenue to support the purchase and use of a small number of ZEBs, which cost from 350,000 to 500,000 euros [10]. Some extra revenue could also be used to cover losses and anticipate the public transportation system reform.

\subsection{Recommendations for practice}

Public marketing tools need to be sourced by public administration, such as public transportation companies [15], [38]. Although both noise and air pollution pose grave consequences for human health [39] and WTP is seen as an indicator of commitment towards new and clean technology [29], public transportation agencies need to focus their marketing efforts in what consumers most value, in order to achieve common benefits.

According to the study's results, the environmental attitudes of the consumers are not correlated with positive attitudes towards ZEBs. Hence, it is not advisable to use an environmental-base marketing plan, neither of noise pollution, which was not correlated with ZEBs attitudes neither with WTP. On the other hand, air pollution concern is correlated with the output variables. It is recommended that campaign plans are defined aiming to inform and educate the consumer about the air quality benefits of ZEBs, thus paving a way into the WTP acceptance and participation. However, care must be taken when selecting the appropriate way to communicate, as an emphasis on the costs of competition (i.e. breathing problems) may be less well-received than an emphasis on clear air positive benefits (i.e. less stress, more attention, better sleep) [15]. In this study it is evident that citizens are concerned about their health, so it is here recommended that this is communicated accordingly, associating it with healthcare facilities and publish posters in clinics, businesses and schools to bring about awareness on air quality. By bringing emphasis on the health risks caused by pollution, public transport agencies can prompt consumers to adopt behaviors to reduce the use of personal cars [40]. Climate events could also be leveraged as triggers: heavy smog or prolonged weather effects can increase the environmental concern on people and trigger pro-environmental behavior, due to a phenomenon of eco-anxiety. It is recommended taking advantage of these events as well as regular data from city atmosphere to develop the marketing strategy.

Additionally, service providers should consider consumers' reception if mixed-fleet solutions are used. Although mixed-fuel fleets are a good solution as this allows routes and infrastructure to be distributed in the most optimized way [41], consumers who are not directly served by the ZEBs can feel at disadvantage for paying a more expensive bus fare to serve other parts of the city. This would be visible especially among populations who live in farther urban areas who would be likely served by diesel buses. 
Competitors of public agencies are organizations that offer similar products or services to the customers, at similar prices, and identifying them is a crucial step for public agencies. For the public transportation sector, competitors are private cars, but also automotive dealerships, car rental services and private transport companies. All of these are private profit-oriented businesses, bringing out the need for the public transportation companies to battle against their marketing and customer-oriented actions. One of the best moments to influence a public behavior is when they are about to choose between competing behaviors - the point of decision making [15]. Rather than promoting ZEBs in buses, bus stops and in city centers, the use of 'just in time' messages when consumers are deciding to take the car could be more effective. Some examples could be wall-mounted key hangers for home, advertisements in parking lots, garages and in high-traffic areas.

In a final note, practitioners should seek to lower barriers to change to use public transportation. Identifying barriers to change is a crucial step in adapting behavior. It is recommended for public transport managers to understand which barriers exist for non-users: as it was noted in the results, almost all of the respondents gave suggestions to improve the service, some corresponding to a basic level of service quality (e.g. buses on schedule, more buses on peak hours). Further insights could be obtained by surveying the population: for example, would people living in a specific suburb have less compatible schedules? Do senior citizens have trouble understanding the maps with the routes? Maybe the buses are too filled at peak time when arriving near the financial district, and workers must wait at the bus stop for the next buses - more trips at certain times or larger buses could lower the barrier for this segment? Moreover, ZEBs have relative advantages over conventional fuel buses: one particular advantage is the possibility of having indoor bus stops, as ZEBs have no emissions [42]. This would allow passengers to wait protected from the weather elements, and could be a strong selling point for regions with adverse winter or summer conditions.

\subsection{Limitations and future research venues}

As any study, there are some limitations. One limitation of this study is the young age of the sample, as $75 \%$ of the respondents are under 35 years old. This study also employed an online survey to measure profile traits, which can lead to inaccuracy as participants answer by interpreting their own emotions and feelings without any sort of help or control from the researcher. This study focused on a single city: in public bus service research there have been observed various levels of satisfaction and willingness to pay [24, 28]. Although the results of this study are applicable to Ekaterinburg and other cities close by, more regions and countries need to be studied to assure conclusions generalization.

In this study, a one item scale was selected to measure environmental concern, however a large number of more complete and extensive scales exist in the literature, such as the 15-item scale from [43]. A more accurate picture could be obtained considering environmental behavior rather than environmental concern [26]. Although the link between the consumers' environmental concern and their behavior is debatable [27], [44], further research could be made into the WTP for ZEBs considering environmental behavior [35].

It is also possible to measure in further detail the pollution variables. Future studies could tackle this limitation, taking examples from studies with a stronger focus on peoples' disturbance sources specifically asking respondents about the air and noise pollution sources they face, such as road traffic, aircraft, and industries, and on which times and levels during the day they are exposed to [32], [33], [45]. Air and noise sensitivity and annoyance could also be incorporated in more detailed studies, as the medical and psycho-social symptoms such as 
sleep disturbance and other questions about the respondents' health [31], [46]. Fyhri and Klæboe [31] further note that commuting context can influence noise sensitivity: as Ekaterinburg covers a large area and is densely populated, it is likely that most people do not commute outside the city, being full time within the city, thus more prone to a continuous noise exposure.

Another limitation is the generalization of WTP value. In a country with a low priced fare the relative WTP can be very high (100\% or $200 \%)$. This situation was found in other studies: for example, using data from the AcceptH2 surveys, some researchers compare the WTP in percentage of cities from different countries [29]. This technique can be misleading, as there are many variables that can influence this value (e.g. salary or fare cost). A new research avenue would be to take into consideration these variables and compare the ration among countries. Future research could measure the 'relative cost' of the fare when compared to living costs (including the use of personal transportation). The WTP absolute and relative values could vary among countries and among regions, and these insights could be valuable for both research and practice.

Finally, the level of exposure to the technology is another variable worthy to be addressed as a predecessor of WTP. Consumers who see public demonstrations and are more informed about ZEBs (e.g. by newspapers) may be more likely to have a better attitude and WTP intentions. Additionally, the public's rival attitudes towards other also eco-friendly and less expensive to purchase modes of transportation (such as tram) could be addressed. It is common view that electric trams are more environmentally friendly than buses, especially due to the absence of batteries, low-friction locomotion system and simpler mechanics.

\section{REFERENCES}

[1] Corazza, M.V., Guida, U., Musso, A. \& Tozzi, M., A new generation of buses to support more sustainable urban transport policies: A path towards 'greener' awareness among bus stakeholders in Europe. Research in Transportation Economics, 55, pp. 20-29, 2016, https://doi.org/10.1016/j.retrec.2016.04.007

[2] Lajunen, A. \& Lipman, T., Lifecycle cost assessment and carbon dioxide emissions of diesel, natural gas, hybrid electric, fuel cell hybrid and electric transit buses. Energy, 106, pp. 329-342, 2016, https://doi.org/10.1016/j.energy.2016.03.075

[3] Tong, F., Hendrickson, C., Biehler, A., Jaramillo, P. \& Seki, S., Life cycle ownership cost and environmental externality of alternative fuel options for transit buses. Transportation Research Part D: Transport and Environment, [Transport. Res. Part D 57 (2017) 287-302], 65, p. 858, December 2018.

[4] Lin, B. \& Tan, R., Are people willing to pay more for new energy bus fares? Energy, 130, pp. 365-372, 2017, https://doi.org/10.1016/j.energy.2017.04.153

[5] Mulley, C., Hensher, D.A. \& Cosgrove, D., Is rail cleaner and greener than bus? Transportation Research Part D: Transport and Environment, 51, pp. 14-28, 2017, https://doi.org/10.1016/j.trd.2016.12.004

[6] Ionescu, G., Apostol, T., Rada, E.C., Ragazzi, M. \& Torretta, V., Critical analysis of strategies for PM reduction in urban areas. UPB Scientific Bulletin, Series D: Mechanical Engineering, 75(2), pp. 175-186, 2013.

[7] Zhou, B., Wu, Y., Zhou, B., Wang, R., Ke, W., Zhang, S. \& Hao, J., Real-world performance of battery electric buses and their life-cycle benefits with respect to energy consumption and carbon dioxide emissions. Energy, 96, pp. 603-613, 2016, https://doi. org/10.1016/j.energy.2015.12.041 
[8] Bakker, S. \& Konings, R., The transition to zero-emission buses in public transportThe need for institutional innovation. Transportation Research Part D: Transport and Environment, 64, pp. 204-215, 2017, https://doi.org/10.1016/j.trd.2017.08.023.

[9] Lajunen, A., Energy consumption and cost-benefit analysis of hybrid and electric city buses. Transportation Research Part C: Emerging Technologies, 38, pp. 1-15, 2014, https://doi.org/10.1016/j.trc.2013.10.008

[10] Mahmoud, M., Garnett, R., Ferguson, M. \& Kanaroglou, P., Electric buses: A review of alternative powertrains. Renewable and Sustainable Energy Reviews, 62, pp. 673-684, 2016, https://doi.org/10.1016/j.rser.2016.05.019

[11] Ibraeva, A. \& de Sousa, J.F., Marketing of Public Transport and Public Transport Information Provision. Procedia-Social and Behavioral Sciences, 162, pp. 121-128, 2014, https://doi.org/10.1016/j.sbspro.2014.12.192

[12] Mohamed, M., Ferguson, M. \& Kanaroglou, P., What hinders adoption of the electric bus in Canadian transit? Perspectives of transit providers. Transportation Research Part D: Transport and Environment, 64, pp. 134-149, 2018, https://doi.org/10.1016/j. $\operatorname{trd}$.2017.09.019

[13] Genon, G., Magaril, E., Magaril, R., Abrzhina, L., Panepinto, D. \& Viggiano, F., Sustainability in automotive transport: Russian and Italian experience concerning actual situation and intervention tools. International Journal of Sustainable Development and Planning, 11(4), pp. 603-615, 2016. https://doi.org/10.2495/sdp-v11-n4-603-615

[14] Magaril, E., Magaril, R., Panepinto, D., Genon, G., Ravina, M., Trushkova, L. \& Zanetti, M.C., Production and utilization of energy and climate adaptation: Global tasks and local routes. International Journal of Sustainable Development and Planning, 12(8), pp. 1326-1337, 2017, https://doi.org/10.2495/sdp-v12-n8-1326-1337

[15] Kotler, P.T. \& Lee, N.R., Marketing in the Public Sector: A Roadmap for Improved Performance. Pearson Education, New Jersey, p. 332, 2007.

[16] Leontyeva, Y.V. \& Mayburov I.A., Theoretical framework for building optimal transport taxation system. Journal of Tax Reform, 2(3), pp. 193-207, 2016. http://dx.doi. org/10.15826/jtr.2016.2.3.024

[17] Mayburov, I. \& Leontyeva, Y., Assessment of tax burden on the ownership and use of road passenger transport in Russia. International Journal of Sustainable Development and Planning, 12(3), pp. 599-605, 2017. http://dx.doi.org/10.2495/SDP-V12-N3-599-605

[18] Mayburov, I. \& Leontieva, Y., Fiscal instruments for regulating the sustainable development of urban transport systems in Russia. IOP Conference Series: Earth and Environmental Science, 72(1), pp. 012016, 1-8, 2017. http://dx.doi.org/10.1088/1755-1315/72/1/012016

[19] Söllner, F., Road traffic taxation in Germany: the present system, its problems and a proposal for reform. Journal of Tax Reform, 4(1), pp. 57-72, 2018. http://dx.doi. org/10.15826/jtr.2018.4.1.045

[20] Heo, J.Y. \& Yoo, S.H., The public's value of hydrogen fuel cell buses: A contingent valuation study. International Journal of Hydrogen Energy, Elsevier Ltd, 38(11), pp. 4232-4240, 2013, https://doi.org/10.1016/j.ijhydene.2013.01.166

[21] Saxe, M., Folkesson, A. \& Alvfors, P., A follow-up and conclusive report on the attitude towards hydrogen fuel cell buses in the CUTE project-From passengers in Stockholm to bus operators in Europe. International Journal of Hydrogen Energy, 32(17), pp. 4295-4305, 2007, https://doi.org/10.1016/j.ijhydene.2007.07.050

[22] Istamto, T., Houthuijs, D. \& Lebret, E., Willingness to pay to avoid health risks from road-traffic-related air pollution and noise across five countries. Science of the Total Environment, pp. 420-429, 497-498, 2014. https://doi.org/10.1016/j.scitotenv.2014.07.110 
[23] Sánchez, M., López-Mosquera, N., Lera-López, F. \& Faulin, J., An Extended Planned Behavior Model to Explain the Willingness to Pay to Reduce Noise Pollution in Road Transportation. Journal of Cleaner Production, 177, pp. 144-154, 2018, https://doi. org/10.1016/j.jclepro.2017.12.210

[24] Altmann, M., Schmidt, P., O’Garra, T., Hart, D., Mourato, S. \& Rohr, C., Accept H2: Public Perception of Hydrogen Buses in Five Countries. International German Hydrogen Energy Congress, pp. 1-13, February 2004.

[25] Stern, P., Dietz, T. \& Kalof, L., Value Orientations, Gender, and Environmental Concern. Environment and Behavior, 25(5), pp. 322-348, 1993, https://doi. org/10.1177/0013916593255002

[26] Fransson, N. \& Gärling, T., Environmental concern: Conceptual definitions, measurement methods, and research findings. Journal of Environmental Psychology, 19(4), pp. 369-382, 1999, https://doi.org/10.1006/jevp.1999.0141

[27] Roberts, J.A., Green consumers in the 1990s: Profile and implications for advertising. Journal of Business Research, 36(3), pp. 217-231, 1996.

[28] Corazza, M.V., Guida, U., Musso, A. \& Tozzi, M., A European vision for more environmentally friendly buses. Transportation Research Part D: Transport and Environment, 45, pp. 48-63, 2016, https://doi.org/10.1016/j.trd.2015.04.001

[29] Haraldsson, K., Folkesson, A., Saxe, M. \& Alvfors, P., A first report on the attitude towards hydrogen fuel cell buses in Stockholm. International Journal of Hydrogen Energy, 31(3), pp. 317-325, 2006, https://doi.org/10.1016/j.ijhydene.2005.11.008

[30] Beaudoin, J., Farzin, Y.H. \& Lin Lawell, C.Y.C., Public transit investment and sustainable transportation: A review of studies of transit's impact on traffic congestion and air quality. Research in Transportation Economics, 52, pp. 15-22, 2015, https://doi. org/10.1016/j.retrec.2015.10.004

[31] Fyhri, A. \& Klæboe, R., Direct, indirect influences of income on road traffic noise annoyance. Journal of Environmental Psychology, 26(1), pp. 27-37, 2006, https://doi. org/10.1016/j.jenvp.2006.04.001

[32] Gidlöf-Gunnarsson, A. \& Öhrström, E., Noise and well-being in urban residential environments: The potential role of perceived availability to nearby green areas. Landscape and Urban Planning, 83(2-3), pp. 115-126, 2007, https://doi.org/10.1016/j.landurbplan.2007.03.003

[33] Öhrström, E., Skanberg, A., Svensson, H. \& Gidlöf-Gunnarsson, A., Effects of road traffic noise and the benefit of access to quietness. Journal of Sound and Vibration, 295(1-2), pp. 40-59, 2006, https://doi.org/10.1016/j.jsv.2005.11.034

[34] Oiamo, T.H., Luginaah, I.N. \& Baxter, J., Cumulative effects of noise and odour annoyances on environmental and health related quality of life. Social Science and Medicine, 146, pp. 191-203, 2015, https://doi.org/10.1016/j.socscimed.2015.10.043

[35] Berenguer, J., Corraliza, J.A. \& Martin, R., Rural-Urban differences in environmental concern, attitudes, and actions. European Journal of Psychological Assessment, 21(2), pp. 128-138, 2005, https://doi.org/10.1027/1015-5759.21.2.128

[36] Landry, N., Gifford, R., Milfont, T.L., Weeks, A. \& Arnocky, S., Learned helplessness moderates the relationship between environmental concern and behavior. Journal of Environmental Psychology, 55, pp. 18-22, 2018, https://doi.org/10.1016/j. jenvp.2017.12.003

[37] Leiserowitz, A., Climate change risk perception and policy preferences: the role of affect, imagery, and values. Climatic Change, 77(1-2), pp. 45-72, 2006, https://doi. org/10.1007/s10584-006-9059-9 
[38] Kaplan, A.M. \& Haenlein, M., The increasing importance of public marketing: Explanations, applications and limits of marketing within public administration. European Management Journal, 27(3), pp. 197-212, 2009, https://doi.org/10.1016/j.emj.2008.10.003

[39] Vienneau, D., Perez, L., Schindler, C., Lieb, C., Sommer, H., Probst-Hensch, N. \& Röösli, M., Years of life lost and morbidity cases attributable to transportation noise and air pollution: A comparative health risk assessment for Switzerland in 2010. International Journal of Hygiene and Environmental Health, 218(6), pp. 514-521, 2015, https://doi.org/10.1016/j.ijheh.2015.05.003

[40] Kasperbauer, T.J., The permissibility of nudging for sustainable energy consumption. Energy Policy, 111, pp. 52-57, July 2017, https://doi.org/10.1016/j.enpol.2017.09.015

[41] Li, L., Lo, H.K., Xiao, F. \& Cen, X., Mixed bus fleet management strategy for minimizing overall and emissions external costs. Transportation Research Part D: Transport and Environment, 60, pp. 104-118, 2018, https://doi.org/10.1016/j.trd.2016.10.001

[42] Tozzi, M., Bousse, Y., Karlsson, M. \& Guida, U., A European Initiative for More Efficient and Attractive Bus Systems: The EBSF-2 Project. Transportation Research Procedia, 14, pp. 2640-2648, 2016, https://doi.org/10.1016/j.trpro.2016.05.421

[43] Dunlap, R.E. \& Van Liere, K.D., The New Environment Paradigm. Journal of Environmental Education, 9(4), pp. 10-19, 1978.

[44] Straughan, R.D. \& Roberts, J., Environmental segmentation alternatives: a look at green consumer behavior in the new millennium. Journal of Consumer Marketing, 16(6), pp. 558-575, 1999, https://doi.org/10.1108/07363769910297506

[45] Öhrström, E., Sleep Disturbance, to Pilot Psycho-Social Survey Among of Road and Medical Exposed Traffic. Journal of Sound and Vibration, 133(1), pp. 117-128, 1989, https://doi.org/10.1016/0022-460x(89)90986-3

[46] Oiamo, T.H., Baxter, J., Grgicak-Mannion, A., Xu, X. \& Luginaah, I.N., Place effects on noise annoyance: Cumulative exposures, odour annoyance and noise sensitivity as mediators of environmental context. Atmospheric Environment, 116, pp. 183-193, 2015, https://doi.org/10.1016/j.atmosenv.2015.06.024 